iRASD Journal of Management

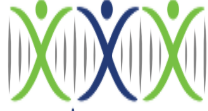

iRASD

Volume 3, Number 3, 2021, Pages 218 - 232

Journal Homepage:

https://journals.internationalrasd.org/index.php/iom

\title{
Employee Empowerment and Compensation as A Consequence on Employee Job Performance with the Moderating Role of Employee Accountability
}

\author{
Muhammad Adnan'1, Samia Zarrar², Kamran Zafar³ \\ ${ }^{1}$ Azteca University (UA), Mexico \& Universidad Central de Nicaragua, Republic of Nicaragua (North America), \\ Email: dr.adnanmalik1989@gmail.com \\ ${ }^{2}$ National College of Business Administration \& Economics (NCBA\&E) Lahore, Multan Sub-campus, Pakistan. \\ ${ }^{3}$ National College of Business Administration \& Economics (NCBA\&E) Lahore, Multan Sub-campus, Pakistan.
}

\section{ARTICLE INFO}

\section{Article History:}

Received:

Revised:

Accepted:

November 12, 2021

December 28, 2021

December 28, 2021

Available Online: December 29, 2021

\section{Keywords:}

Employee Empowerment Employee Compensation Employee Accountability Employee Job Performance FMCG

\section{ABSTRACT}

Using data from 200 employees of FMCG companies in Multan, this study aims to analyze the effect of Employee Empowerment and Employee Compensation on Employee Job Performance while moderating the role of Employee Accountability. Partial least square method is used to estimate the results. The results of PLS-SEM reveal that Employee Empowerment, Employee Compensation, and Employee Accountability are all positively and significantly related to Employee Job Performance. Employee Accountability was found to partially moderate the relationship between Employee Empowerment and Employee Compensation using moderated regression. It is recommended that, in order to improve employee job performance, the organization develop and implement strategies for providing appropriate compensation. After processing and analyzing information from the labor market and internal regulations of the company, there seems a need to modify an appraisal system in line with the specified compensation structure and other benefits.

(c) 2021 The Authors, Published by iRASD. This is an Open Access article under the Creative Common Attribution Non-Commercial 4.0

OPEN

ACCESS article under the Creative Com

\section{Introduction}

To accomplish goals and objectives, organizations have to adapt constantly to their environment. Organizations need innovative methods for handling business, providing services and products to consumers in an intensely dynamic environment and changing business. There are rapid developments in economies, goods, technologies and competitive pressures. Therefore, all organizations must be able to quickly respond to these developments. Empowering workforce is the long-term method of supplying the workforce with the resources, preparing and encouraging them to deliver at the highest level. Empowerment creates a sense of sovereignty for workers, which would increase employee happiness. At work, it would be more relaxed and it develops self-confidence and a feeling of esteem (Mohapatra, 2018).

Employee empowerment refers to the allocation of authority and obligation to lowerlevel workers from senior management in the organizational hierarchy, especially the power to make decisions (Arneson, 2005). The usage of knowledge, talents and skills by the population is improved. It supports collaborative work and where there is constructive engagement, it will contribute to the effective introduction of initiatives for improvement (Sundaray, 2018). Employee performance has a positive association to the overall performance of job and progress of an enterprise (Snell, 2010). Therefore, ensuring empowerment of employees at their utmost capacity, is critical for organizations. 
Employee performance is regarded as a critical concern in today's dynamic business environment around the world, not only for attaining goals of organization but also for preserving competitive advantages over other businesses. To improve the performance of employees, all organizations must encourage positive attitudes in the workplace, such as assisting customers with problems, cooperating with coworkers, attempting to avoid unexpected incidents, and adhering to the organization's quality standards to ensure customer satisfaction (Yilmaz, 2015). One of the most successful ways of assisting workers in using their creative skills to improve their performance within the business they work for is via empowerment. Clear communication channels are required to build successful empowering employees. This will need management spending more time talking with employees and allowing for feedback. Furthermore, it is necessary for management to assess the institution's communication styles and procedures in order to assure the most effective processes practicable (Abou Elnaga, 2014). Given unpredictable technology development, unstable environments, and rising competition, an increasing number of firms are recognizing the need of giving their workers the authority and confidence they need to be effective (Shalley \& Gilson, 2004).

On the contrary Employee compensation is also important in influencing the performance of employees. During the process, there is an issue with employee compensation and benefits. This is because, on occasion, unfair compensation is given to employees as a result of the manager's bias. The allowances are not based on reasonable standards (Feraro-Banta, 2017). Furthermore, many employees are not well aware of their compensations and benefits as a part of appraisal system. The majority of employees believe that compensations and benefits are solely valued in monetary terms. Compensations and benefits are typically limited to financial worth and in consequence, companies have a shaft vision when it comes to comes to Employee well-being (TettehAnnor, 2014).

The main goal of this investigation is to look into the impact of employee empowerment and employee compensation on employee job performance while moderating the effect of employee accountability in the FMCG sector. Empowerment is now a critical tool in organizations for improving employee job performance. Accountability is another important tool that has a significant impact on employee job performance. There is little research on the role of accountability as a moderating variable in the association between employee empowerment and job performance. The outcomes of this study on the impact of employee empowerment and compensation on performance of employees will be added to the existing body of literature in Pakistan's FMCG sector. This study will provide managers and executives in the FMCG sector with insights into how empowerment and compensation affect employee job performance, with employee accountability acting as a moderator. Managers and leaders will be able to better understand their employees' perceptions of empowerment as a result of this information. It will also assist managers and leaders in better managing their employees, resulting in improved individual and organizational performance.

\section{Literature Review \\ 2.1. Employee Performance}

The performance of employees as the extent to which an employee fulfils assigned duties and responsibilities (Shields, 2015). However, the concept of employee success is demonstrated from a specific perspective. According to their observation, in general performance criteria, performance of employees cannot be described and can only be clarified in the light of organizational circumstances and viewpoints (Richard, 2009).

\subsection{Employee Empowerment}

Empowerment is defined as the act of allowing individuals to make decisions at work by exercising their decision-making autonomy. Employee Empowerment allows workers a certain degree of choice and transparency for their particular operational roles and decisionmaking (Dobre, 2013). The empowerment as job autonomy management, coordination variance, and compensation structures that connect compensation to success. He further separated empowerment into four groups, which are the leadership role in establishing the 
framework of empowerment, the human viewpoint of empowerment, collective work as empowerment, and systemic and procedural reform as empowerment, aimed at transforming corporate policy with the goal of enhancing the capacity of both individuals and organizations to function and boost results.

\subsection{Employee Compensation}

Compensation is a monetary reward or incentive given to an employee in exchange for providing services to an employer. Salaries, wages, incentives and bonuses are frequently used (Geralyn, 2007). Compensations are awarded as a result of exchange between employees and organization, either as a right to stay in the organization or as a reward for a job done in a well manner (Brown, Sturman, \& Simmering, 2003). It is not always the case that those are compensated who has done a good job. Employees may fall short of expectations, but due to Trade Union Congress laws and regulations, they can still be paid. Compensation is based on an employee abilities, expertise, experience, and education. Compensation is a particularly important issue since it frequently has a substantial impact on a firm's recruiting and retention efforts. According to Allen, Bryant, C., and Vardaman (2010), if firms are unable to adequately compensate applicants, they will be unable to attract or retain essential skills or expertise required to function efficiently and effectively. In the field of human resource management, compensation is the second most researched issue (Henderson \& Tulloch, 2008).

\subsection{Employee Accountability}

Accountability is defined as the implied or obvious expectation of being called upon to justify one's ideas, feelings, and behaviors to others (Lerner \& Tetlock, 1999). It describes the degree to which others observe and evaluate an individual's actions, with considerable rewards and penalties based on such evaluations (Dulebohn, Ferris, \& Stood, 1995). Radin, A., Dubnic, J., and Frederickson (2011) distinguished between pre- and postfactum accountability. Pre-factum accountability is used to change conduct before it occurs, whereas post-factum accountability is used after it has occurred. However, it may be difficult to distinguish among the competitive employees in some cases. Sanctions, for example, can be used to penalize for bad behavior, but they can also be used to avoid it. Indeed, post-factum responses are founded on pre-factum accountability because poor performance can be avoided by imposing sanctions. As a result, both kinds can be viewed as an institutional mechanism for convincing employees to behave and perform appropriately, such as through monitoring. Individuals, groups, and organizations can all be significantly influenced by such responsibility, which was created to deal with the various expectations and responsibilities generated both inside and outside of public organizations (Hong, 2017).

\subsection{Relationship between Employee Empowerment and Employee Performance}

Al-Makhadmah, Najdawi, M., and Al-Muala (2020) examined the influence of psychological empowerment on the performance of employees. According to the findings, sense and self-determination have an effect on employee efficiency, whereas effect and skill have no effect on employee performance. Furthermore, while education has a significant impact on the relationship between consequences and performance of employees, the association between purpose, skill, and self-determination is unchanged.

Bose and Emirates (2018) investigated the influence of employee empowerment on performance in the UAE banking sector. Employees in the UAE banking industry were found to be unmotivated to improve their performance in the current environment. Finally, in the current banking case, the association between empowerment of employees and employee Success was discovered to be non-existent. Employee Empowerment and Organizational Performance were investigated by (Nadeem, Zia-uD-din, Riaz, Shafique, \& Sattar, 2018). The study's findings revealed that with the motivational mediator component, employee empowerment frequently explained an important association with corporate success. 
Hanaysha (2016) analyzed the impact of three influences on organizational performance in Malaysian higher education, namely staff empowerment, collaboration, and staff preparation. The results revealed that the empowerment of workers has an optimistic influence on organizational engagement. It was also found that the impact of teamwork on organizational engagement was positive and statistically important. Lastly, the results indicated that preparation of workers has a major affirmative influence on organizational engagement. Empowerment plays an imperative role in increasing the success of workers. In order to assess the views of workers employed on different software projects about empowerment activities and their perceived job performance, a survey was performed using a self-administered questionnaire (Arslan \& Zaman, 2014). The net impact on work efficiency of institutional and psychological empowerment is significantly positive. Employees who are motivated structurally and mentally positively predict work efficiency. Iqbal, Ahmad, and Javaid (2013) explored the influence of worker's empowerment on the efficiency of employees. The outcome revealed the substantial association between empowerment and the performance of employees.

\subsection{Relationship between Employee Compensation and Employee Performance}

According to Dessler (2011), employee compensation includes all types of pay or promotions given to and received by workers, and it can include both direct financial payments (pay in the form of wages, pensions, promotions, fees, and bonuses) and indirect financial payments (pay in the form of financial benefits such as insurance).

Some well-known researchers examined the relationship between pay and job success and presented their findings in a direct study. For example, Bajor and Baltes (2003) calculated and studied that there is an efficient and strategic association between compensation and performance of job results using selection optimization-compensation. The other study Mehran (1995) found an optimistic association between work performance and equity-based compensation policies, indicating that equity-based compensation is becoming more common in businesses to ensure optimum performance. An interaction between work efficiency, satisfaction of job, and individual personality differences was discovered that are also linked to pay policies (Arnolds \& Boshoff, 2002).

In Nigeria, Okeke and Ikechukwu (2019) investigated the effects of compensation management on job performance of employees. Equity-based pay has little adverse effects on job success in a company in Nigeria. Competency-based pay has little adverse effects on job efficiency in a company in Nigeria. Workers' performance in Nigeria should not suffer as a result of performance-based pay. The analysis then concluded that compensation management has a substantial impact on performance of job in Nigeria. Akram (2018) investigated the effects of preparation and reward on work outcomes, as well as the moderating role of motivation. The study discovers that preparation and incentives have a positive impact on work results, but there is no evidence of motivation acting as a moderator. The results exposed that preparation has a substantial impact on the success of the work, as predicted. The findings also exposed that pay has a significant and optimistic influence on work outcomes.

In a case study of Mombasa Cement Limited, Jean, K., and N.K (2017) examined the impact of compensation strategies on employee outcomes. The study showed that fair pay, compensation, and appreciation through certification or orally encouraged job success in the form of incentives and allowances. In conclusion, a very high gap in the organization's reaction to standard compensation suggests that workers were fully conscious of this and that it was actually occurring. Correct approach and policy-based compensation scheme could boost the worker's job efficiency (Akter, 2016). Compensation thus has a substantial impact on work efficiency. The quantitative analysis demonstrated that the relationship between compensation and work results was good and optimistic. 


\subsection{Relationship between Employee Accountability and Employee Performance}

Han and Hong (2019) explored the association between organizational performance and accountability at 03 levels in Human Resource Management (HRM) hiring functions, appraisal measurement, and pay as viewed by public organization workers. In addition, this research explores whether the degree of control experienced by the workers affects the relationship between transparency and efficiency. The results showed that the standards of transparency reflected in recruitment, success appraisal, and compensation all have a direct and substantial influence on performance of organization. In comparison, employee autonomy continues to intensify the beneficial influence of accountability on performance in staffing and compensation for two HRM tasks.

An axiom in modern culture has been accountability, in organizational life, as a foundational factor (Ferris, Mitchell, Canavan P. J., D., \& Hopper, 1995). It appears intuitive to the idea of accountability; it is something people feel when they have to answer for their actions i.e., the expectation of justifying why you are late for work to the boss. But, for professionals and scholars alike, many of the dynamic properties that control the subjectivity of accountability remain elusive. Contradictory study reports are contributing to the mystery, prompting more study intended at determining factors accountable for these inappropriate effects (Hall, Frink, Ferris, A, \& G, 2003).

A recent review shows a negative perception \& effect on individual responsibilities \& involvement with the delegated role of accountability. Where strategic \& behavioral decision making is involved where no financial considerations are concerned, this pattern is more likely to be encountered; rather the decision of the individual about their motivating efforts \& ownership sense of performing duties such as role of work success is discussed. Employees fail to take action under such situations where, after being motivated, responsibility with respect to their work results would pull them into an uncomfortable situation. Accountability can have detrimental effects (Kroon, Van Kreveld, \& Rabbie, 1992). Accountability, if the forum's expectations are established, induces enforcement rather than critical analysis of the decisional dilemma (Tetlock, 1985). In order to assess the moderating impact of accountability on the relationship between employee empowerment and work efficiency, the following theory is thus suggested. Based on the review of literature it is assumed that:

\section{Conceptual Framework}

Figure 1 displays the conceptual model of this research. The dependent variable used in a study is job performance of Employee while independent variables are Employee empowerment and Employee compensation. The moderation variable is Employee accountability.

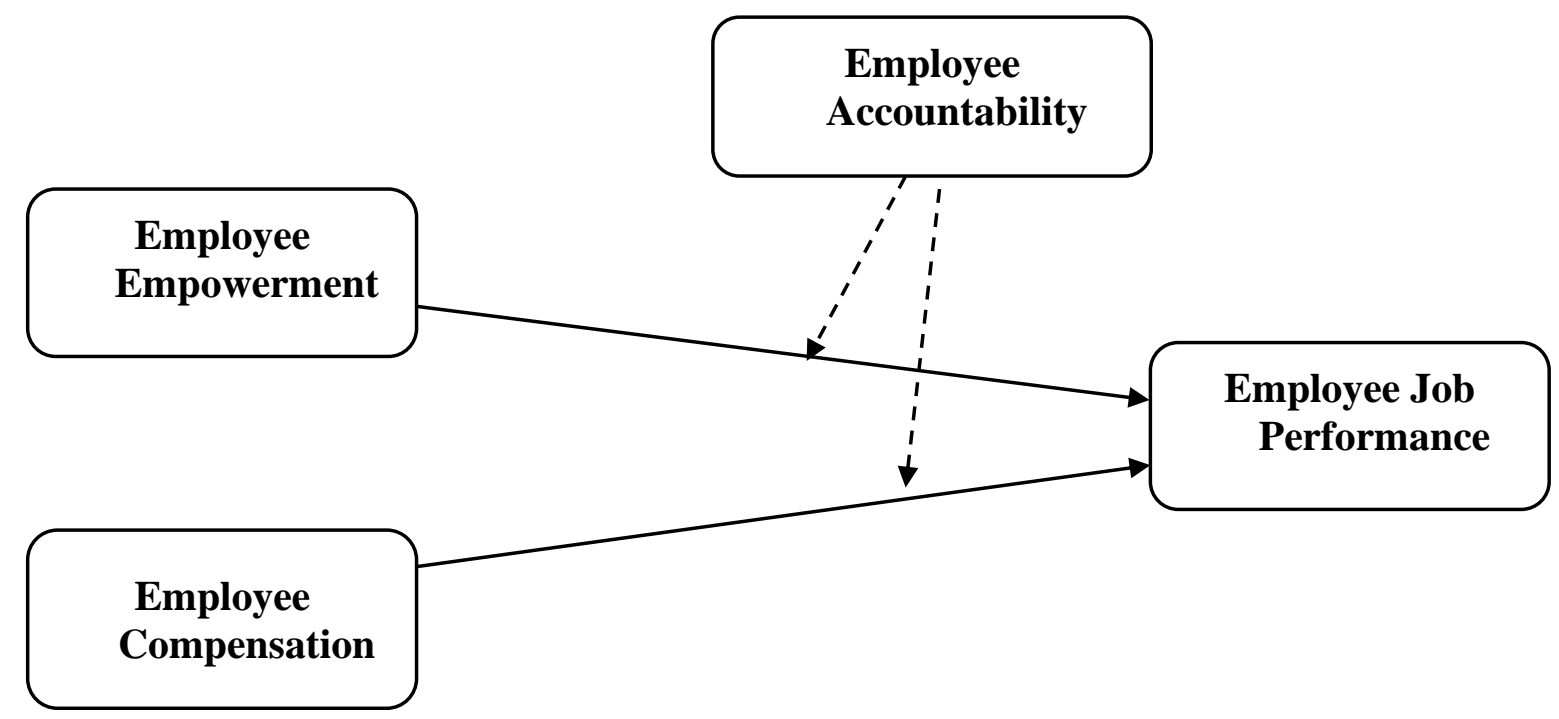

Figure 1: Conceptual Model 


\subsection{Methodology}

3.2. Research Design

A research design is a broad framework for gathering and analyzing data. Exploratory, descriptive, and causal study designs are the three most common types of study designs (Kamunge, S, Njeru, \& I., 2014). We used a descriptive design in our study. Descriptive research design is a method of gathering raw data and constructing data structures that describe the existing characteristics of the target population (e.g., attitude intentions, purchasing habits, and appraisal of current marketing mix methods). The descriptive research method is appropriate for studies aimed at determining the relationship between various variables.

\subsection{Population}

The study includes all employees of FMGC companies in Multan region of Pakistan as a population.

\subsection{Sampling Techniques and Data Sources}

This study relies on primary sources of data. A convenient sampling technique was utilized to gather data from 200 employees of FMCG companies in Pakistan's Multan region. The questionnaire is used as a research instrument to collect data.

\subsection{Model Specification}

Two models were developed to assess the influence of employee empowerment and employee compensation on employee job performance with the moderation of employee accountability.

\section{Model-1: Investigates Impact of Employee Empowerment and Employee Compensation on Employee Performance}

$\mathrm{EMP}=\beta_{\mathrm{o}}+\beta_{1} \mathrm{EME}+\beta_{2} \mathrm{EMC}+\beta_{3} \mathrm{EMA}+u_{i}$

Where;

EMP: Employee job performance

EME: Employee empowerment

EMC: Employee compensation

EMA: Employee accountability

Model-II: Investigates Impact of Employee Empowerment and Employee Compensation on Employee Performance with moderation of Employee Accountability

$\mathrm{EMP}=\beta_{\mathrm{o}}+\beta_{1} \mathrm{EME}+\beta_{2} \mathrm{EMC}+\beta_{3} \mathrm{EMA}+\beta_{4} \mathrm{EME} * \mathrm{EMA}+\beta_{5} \mathrm{EMC} * \mathrm{EMA}+u_{i}$

Where;

EMP: Employee job performance

EME: Employee empowerment

EMC: Employee compensation

EMA: Employee accountability

EME*EMA: Interaction term of employee empowerment and employee accountability

EMC*EMA: Interaction term of employee compensation and employee accountability

\subsection{Methodological Issues}

Different econometric techniques are applied to attain the objectives of the study. Cronbach's Alpha data reliability measurement is used to evaluate the reliability of the data. 
The partial least square approach is utilized to analyze the impact of employee empowerment and employee compensation on Employee job performance with moderating the role of Employee accountability. Researchers must go through a multi-stage method when utilizing PLS-SEM, which involves establishing the inner and outer models, collecting and reviewing data, estimating the model, and assessing the results (Hair, Ringle, \& Sarstedt, 2014).

\section{Hypotheses Development}

Based on the literature review, following hypotheses are developed:

$\mathbf{H}_{\mathbf{1}}$ : EME positively influences the EMP.

$\mathbf{H}_{2}$ : EMC positively influences the EMP.

$\mathbf{H}_{3}$ : EMA positively influences the EME.

$\mathbf{H}_{4}$ : EMA significantly moderates the relationship between EME and EMP.

$\mathbf{H}_{5}$ : EMA significantly moderates the relationship between EMC and EMP.

\section{Analysis}

\subsection{Descriptive Analysis}

The descriptive statistics of variables are explained in this section. The mean value of data, maximum value, minimum value, standard deviation, skewness, and kurtosis are explored as the main characteristics of all variables. Table 1 reports the descriptive statistic of variables. The mean of age of respondents found in a survey, is 34.080 years; maximum age is 51.0 years; minimum age is 23.0 years; standard deviation is 5.528 ; the value of skewness is 0.760 and kurtosis value is 3.772 . Similarly, the descriptive statistics of aforementioned variables can be analyzed from Table 1.

\section{Table 1}

\section{Descriptive Statistics of Constructs}

\begin{tabular}{lllllll}
\hline Variables & Mean & MAX & MIN & S.D. & Skewness & Kurtosis \\
\hline AGE & 34.080 & 51.0 & 23.0 & 5.528 & 0.760 & 3.772 \\
EDU & 14.890 & 18.0 & 10.0 & 1.767 & -0.512 & 2.942 \\
MINC & 37264.50 & 94000.0 & 15000.0 & 15074.590 & 1.302 & 5.556 \\
EMA & 23.685 & 30.000 & 12.000 & 4.135 & -0.708 & 2.444 \\
EME & 27.035 & 35.000 & 10.000 & 5.846 & -1.174 & 3.462 \\
EMP & 15.955 & 20.000 & 6.000 & 3.110 & -0.986 & 3.309 \\
EMC & 19.790 & 25.000 & 8.000 & 3.268 & -1.276 & 4.998 \\
\hline
\end{tabular}

Note:

AGE: Age of the respondent, EDU: Education of the respondent, MINC: Monthly income of the respondent, EMA: Employee accountability, EME: Employee empowerment, EMP: Employee performance, EMC: Employee compensation

Source: Author's Calculations

\subsection{Correlation Analysis}

Table 2 presents the Correlation Matrix. It is found that employee performance is positively correlated to employee empowerment (0.769), employee compensation (0.590), and employee accountability (0.762).

\section{Table 2}

\section{Correlation Matrix}

\begin{tabular}{lllll}
\hline Correlation & EMP & EME & EMC & EMA \\
\hline EMP & 1.000 & & & \\
EME & $0.769 * *$ & 1.000 & & \\
EMC & $0.590^{* *}$ & $0.612^{* *}$ & 1.000 & \\
EMA & $0.762^{* *}$ & $0.762^{* *}$ & $0.572^{* *}$ & 1.000 \\
\hline
\end{tabular}

Note: $* *$ Significant at 1 percent level of significance

EMA: Employee accountability, EME: Employee empowerment, EMP: Employee performance, EMC: Employee compensation

Source: Author's Calculations 


\subsection{Measurement Model}

Confirmatory analysis and factor loads are presented in this section.

\subsection{Construct Reliability and Validity}

Confirmatory Factor Analysis (CFA) typically examines the measurement model, including Cronbach's Alpha, rho_A, Composite Reliability, and Extracted Average Variance (AVE). Cronbach's Alpha should be greater than 0.70, and all variables have alpha values greater than 0.70 . Composite reliability should be greater than 0.60 Fornell and Larcker (1981) and Average Variance Extracted (AVE) should be greater than 0.50 (Hair et al., 2014). The results show that the Composite Reliability and Average Variance Extracted (AVE) values are both higher than the cutoff points. As a result, we can conclude that the data used for analysis in a study is extremely reliable.

\section{Table 3}

Construct Reliability and Validity

\begin{tabular}{lllll}
\hline Variables & Cronbach's Alpha & rho_A & Composite Reliability & $\begin{array}{l}\text { Average Variance Extracted } \\
\text { (AVE) }\end{array}$ \\
\hline EMA & 0.817 & 0.85 & 0.872 & 0.579 \\
EMC & 0.768 & 0.764 & 0.797 & 0.506 \\
EME & 0.949 & 0.953 & 0.958 & 0.766 \\
EMP & 0.769 & 0.832 & 0.857 & 0.610 \\
\hline
\end{tabular}

Note: EMA: Employee accountability, EME: Employee empowerment, EMP: Employee performance, EMC: Employee compensation

Source: Author's Calculations

\subsection{Factor Loadings}

\section{Table 4}

Factor Loadings Variables

\section{Employee Accountability}

"I often have to explain why I do certain things at work" 0.706

"Top management holds me accountable for all of my 0.806 decisions."

"If things at work do not go the way that they should, I will hear about it from top management"

"To a great extent, the success of my immediate work group $0.875 \quad$ Supported rests on my shoulders"

"The jobs of many people at work depend on my success or failures"

\section{Employee Compensation}

"Increment in monthly salary has changed employee $\quad 0.771 \quad$ Supported

"Existing salary packages provided by the management reasonable"

"Employees encouraged to acquire skills to get salary increment" attitude"

"Employees are salaried according to position not performance"

"Higher levels of pay have always resulted to greater satisfaction among employees"

\subsection{4}

0.702

0.877

0.718

\section{Employee Empowerment}

"I am allowed to make decisions on my job undertakings"

"I have authority to make autonomous decisions in my job"

"I have opportunities to express my ideas"

0.814

"Power sharing increases my work autonomy"

0.877

"Knowledge sharing would improve work processes in the organization"

"I have access to the information we need to perform our $\quad 0.902$ job"

"My pay encourages me to improve the quality of my work"
0.877

0.833
Not Supported

Supported

Supported

Supported

Supported

Supported

Supported

Supported

Supported

Supported

Supported 
Employee Job Performance

"My performance is better than that of my colleagues with 0.907

Supported similar Qualifications"

"I am satisfied with my performance because it is mostly good"

"My manager discusses regularly on my job performance"

Supported

"I always reach my performance target"

Source: Author's Calculations

Factor loadings reflect how closely items in a construct are related to one another. The factor loading value should be higher than 0.60 (Hair et al. 2007). If the factor loading number is less than 0.60 , it means that items from one construct are correlating with items from another construct and that the intended construct is not being measured. This condition is regarded as a problem that must be addressed. Items with a factor loading of less than 0.60 should be eliminated from investigation. The factor loadings are shown in Table 4. The majority of the items has a factor loading value more than 0.60 , while just a few have a value less than 0.60. Items with a factor loading value of less than 0.60 are thus omitted from the investigation.

\subsection{Structural Equation Modeling}

Table 5 shows the PLS estimates of the influence of Employee Empowerment and Employee Compensation on Employee Job Performance, with Employee Accountability acting as a moderator. Employee Job Performance (EMP) is used as a dependent variable in a model, with Employee Empowerment (EME) and Employee Compensation (EMC) serving as independent variables and Employee Accountability (EMA) serving as a moderating variable. The outcomes of PLS exhibits that the Employee Empowerment, Employee Compensation and Employee Accountability are significantly related to Employee Job Performance. The value of $\mathrm{R}^{2}$ is $\mathbf{0 . 8 8 4}$, indicating that independent variables account for $88.4 \%$ of the variance in the dependent variable (Employee job performance), while the remaining $\mathbf{1 1 . 6}$ percent is attributable to other factors not that are included in the model.

\section{Table 5}

PLS Estimates of Impact of Employee Empowerment and Employee Compensation on Employees Accountability

\begin{tabular}{lllllll}
\hline Variables & Original Sample & Sample Mean & $\begin{array}{l}\text { Standard } \\
\text { Deviation }\end{array}$ & T-Statistic & $\begin{array}{l}\text { P- } \\
\text { Values }\end{array}$ & Result \\
\hline EMA -> EMP & 0.236 & 0.238 & 0.055 & 4.297 & 0.000 & Supported \\
EMC -> EMP & 0.140 & 0.140 & 0.047 & 2.954 & 0.003 & Supported \\
EME -> EMP & 0.626 & 0.624 & 0.060 & 10.424 & 0.000 & Supported \\
R $^{2}$ & 0.884 & & Adjusted-R & & 0.883 & \\
\hline
\end{tabular}

Note: EMA: Employee accountability, EME: Employee empowerment, EMP: Employee performance, EMC: Employee compensation

Source: Author's Calculations

\subsection{Moderation Analysis}

Table 6 shows the PLS estimates of the impact of employee empowerment and compensation on employee performance: moderating impact of employee accountability. In order to investigate the moderating role, the interaction terms Employee empowerment and employee accountability (EME*EMA) and Employee compensation and Employee accountability (EMC*EMA) are added to this model. The outcomes show that the variables Employee empowerment, Employee compensation and Employee accountability positively and significantly related to employee performance as in initial model. On the contrary, at the $10 \%$ level of significance, the interaction term of Employee empowerment and Employee accountability (EME*EMA) is found to be positive and statistically significant ( $T$ stat $=1.926, \mathrm{P}$-value $=0.055)$. It suggests that there is some moderation, and that employee accountability moderates the association between EME and EMP. EMC and EMA interaction term is found to be negative but statistically insignificant ( $t$-stat $=0.260, P$-value $=0.795$ ). It indicates that there exists no moderation and employee accountability does not moderate the association between employee compensation and employee performance. 
Table 6

Moderation Analysis

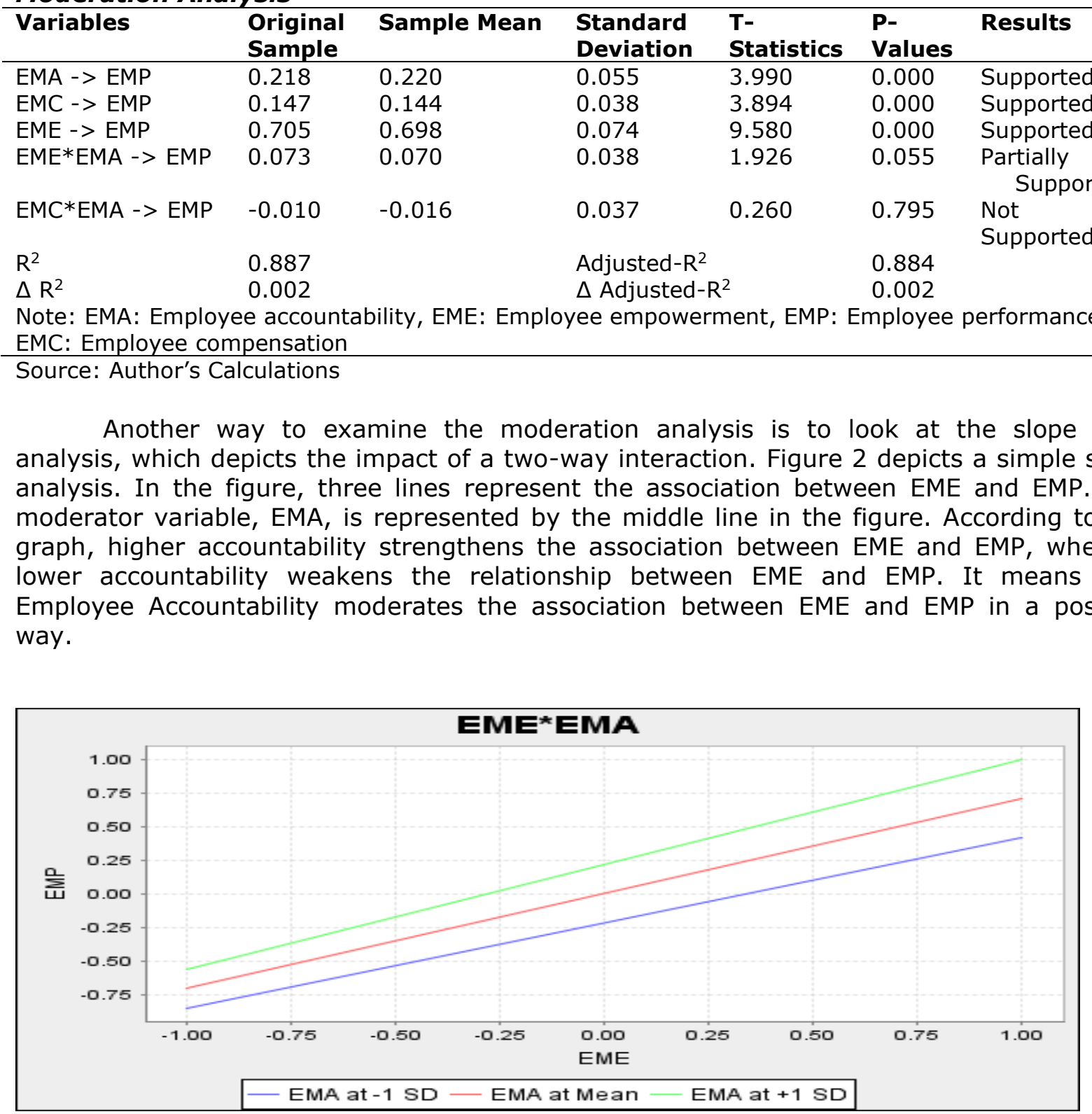

Figure 2: Slope Path Analysis (Employee Empowerment*Employee Accountability)

Source: Author's Calculations

Figure 3 portrays the simple slope analysis. It can be analyzed from the figure that the slope of three lines change at the same rate as moderator variable changes, it indicates no moderation is found.

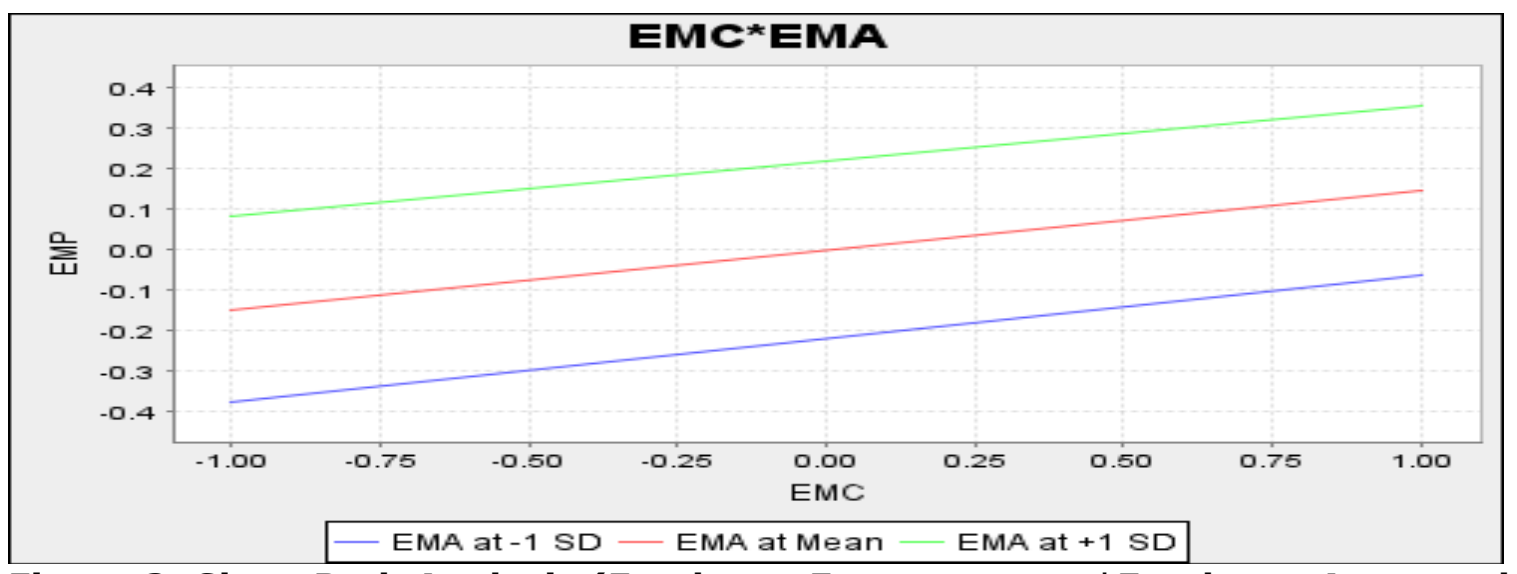

Figure 3: Slope Path Analysis (Employee Empowerment*Employee Accountability)

Source: Author's Calculations 


\subsection{Hypothesis-Wise Discussion}

\section{$\mathrm{H}_{1}$ : The Relationship between Employee Empowerment and Employee Job Performance is Positive}

It is found that the association between employee empowerment and employee performance is statistically significant $(T$-stat $=4.297, P$-value $=0.000)$. The first hypothesis of the study i.e., "The relationship between Employee Empowerment and Employee Performance is Positive" is accepted. Empowerment has a considerable impact on employee satisfaction and, as a result, on organizational performance. By sharing authority, resources, and expertise with each and every employee, job satisfaction and commitment are improved. These are the elements that will have a major impact on individual productivity and effectiveness, as well as the quality of customer interactions (Bowen \& Lawler, 2006). These findings were also found in the studies of (Rajalingam, Y., Jauhar, \& Bashawir, 2015); (Arslan \& Zaman, 2014); (Yilmaz, 2015); (Nadeem et al., 2018).

\section{$\mathrm{H}_{2}$ : The Relationship between Employee Compensation and Employee Job Performance is Positive}

It is found that the association between employee empowerment and employee performance is statistically significant as well $(T$-stat $=2.954, P$-value $=0.003)$. The second hypothesis of the study i.e., "The Relationship between Employee Compensation and Employee Performance is Positive", is accepted. Compensation and benefit packages have improved human resource outcomes, such as performance, satisfaction, and productivity. If an employee compensation is linked to their productivity, the quality and amount of work produced can improve (Ivancevich, W. F., \& Glueck, 1989). These findings are also confirmed in the studies of (Hameed, Ramzan, Zubair, \& K., 2014).

\section{$\mathrm{H}_{3}$ : The Relationship between Employee Accountability and Employee Performance is Positive}

It is also found that the association between Employee Empowerment and Employee Accountability is positive and statistically significant $(T$-stat $=10.424, P$-value $=0.000)$. The third hypothesis of the study i.e., "The Relationship between Employee Accountability and Employee Performance is Positive", is accepted as well. The organization's accountability measures for staffing, performance evaluation, and compensation systems had a positive impact on its performance (Han \& Hong, 2019). These outcomes are also found in the studies of (Han \& Hong, 2019):

\section{$\mathrm{H}_{4}$ : Employee Accountability significantly moderates the relationship between Employee Empowerment and Employee Job Performance}

It is found that Employee accountability partially moderates the association between EME and EMP (T-stat= 1.926, P-value = 0.055). The third hypothesis of the study "Employee Accountability Moderates the Relationship between Employee Empowerment and Employee Performance" is thus accepted too.

\section{H5: Employee Accountability significantly moderates the relationship between Employee Compensation and Employee Job Performance}

Employee accountability is found to moderate the relationship between Employee empowerment and Employee empowerment $(T$-stat $=0.260, P$-value $=0.795)$. The fifth hypothesis of the study, "Employee Accountability Moderates the Relationship Between Employee Compensation and Employee Performance," is rejected.

\section{Conclusions}

This study seeks to examine the impact of Employee Empowerment and Employee Compensation on performance of job, with Employee Accountability serving as a moderator. The response collection included 200 employees from FMCG companies in Multan region. Employee Empowerment, Employee Compensation, and Employee Accountability are all 228 
positively and significantly related to Employee Job Performance, according to the findings of PLS. Employee accountability partially moderates the relationship between Employee empowerment and Employee empowerment, allowing the third hypothesis of the study to be accepted. Employee accountability has been found to moderate the association between employee empowerment and employee empowerment. The study's fifth hypothesis is rejected. Based on the study's findings, it is concluded that employee compensation and employee empowerment positively affect employee job performance, and that organizational managers should work to improve employee empowerment and compensation.

\subsection{Managerial Implication}

Employees, managers, academic researchers, and human resource development experts will all benefit from the results of this study. Despite the significant findings of this study, the literature shows that employee empowerment and compensation research is rarely conducted within Pakistani organizations, particularly in the FMCG sector. As a result, the current study is proposed to present a stronger emphasis on compensation and empowerment, as well as to examine some factors that affect employee job performance in the FMCG sector. Employees who are empowered ensure that they have a variety of options by leveraging their creativity and individual abilities in making quick decisions for effective customer service of dissatisfied customers. Managers must make opportunities or facilities available that should be provided appropriately, and there must be active employee engagement within the establishment. This may lead to opportunities, as well as considering the ideas and expectations of employees regarding operation towards satisfaction, including opportunities for empowerment and consideration of opinions in decision-making processes, which will undoubtedly improve Employee performance. Overall, the public learns from this study that employee empowerment, compensation, and accountability are essential management factors as well as critical to the growth of businesses.

\subsection{Limitations of the Study}

There are some limitations of the study despite the important contribution of the study discussed previously. The study's data was confined to the employees of FMCG employees with a sample size of 200. Further research might use larger sample size and incorporate data from additional cities of Punjab and may also cover other organizations. Different dimensions of empowerment can also be used as a factor of Employee job performance. On the other part, there are some other factors such as working environment, relationship with colleagues, rewards and incentives etc. can also be used as a predictor of Employee performance in further studies.

\subsection{Recommendations}

Based on the findings of the study, following recommendations are suggested to improve Employee performance:

1. Management should pay attention to the work environment since people respond to their working circumstances in order to be productive. It is strongly recommended that management examine its performance evaluation and reward system. Conducting frequent employee accountability, providing emotional support to employees, and creating a climate where employees may approach to management with their issues.

2. Top management should continue to convey the organization's goal and direction to all personnel, since this study aids in business performance monitoring. Every business must ensure that all workers are aware of their duties and responsibilities, as well as that they have adequate resources and a pleasant working environment. This may be accomplished through managerial commitment, which entails ensuring that all workers are aware of how their actions affect firm performance.

3. Employee empowerment practices should be encouraged by management in regional development authorities, according to the research, since this would allow employees to effectively execute their responsibilities. It is the responsibility of management to establish an atmosphere that encourages employee empowerment. 
There is no question that performance enhancement is only possible when a continuous development process is in place.

\section{References}

Abou Elnaga, A., \& Imran, A (2014). The impact of employee empowerment on job satisfaction theoretical study. American Journal of Research Communication, 2(1), 13-26.

Akram, M. S., Khan, A. S., Shah, D. S. M. A., \& Khan, D. J. A. (2018). The Effect of Training and Compensation on Job Performance Accessing the Moderating Role of Motivation A Case Study of Public Sector of Pakistan. Journal of Business and Tourism, 4(2), 39-51.

Akter, N., \& Husain, M. M. (2016). Effect of compensation on job performance: An empirical study. International Journal of Engineering Technology, Management and Applied Sciences, 4(8), 103-116.

Al-Makhadmah, Najdawi, A., M., B., \& Al-Muala, I. M. (2020). Impact of Psychological Empowerment on the Performance of Employees in the Four-And Five-Star Hotel Sector in the Dead Sea-Jordan Tourist Area. GeoJournal of Tourism and Geosites, 30( 2), 896-904.

Allen, D. G., Bryant, C., P., \& Vardaman, J. M. (2010). Retaining talent: Replacing misconceptions with evidence-based strategies. Academy of management Perspectives, 24(2), 48-64.

Arneson, H., \& Ekberg, K (2005). Evaluation of empowerment processes in a workplace health promotion intervention based on learning in Sweden. Health promotion international, 20(4), 351-359.

Arnolds, C. A., \& Boshoff, C. (2002). Compensation, esteem valence and job performance: an empirical assessment of Alderfer's ERG theory. International Journal of Human Resource Management, 13(4), 697-719.

Arslan, M., \& Zaman, R. (2014). Effect of empowerment on job performance: A study of software sector of Pakistan. Research on Humanities and Social Sciences, 4(27), 23-27.

Bajor, J. K., \& Baltes, B. B. (2003). The relationship between selection optimization with compensation, conscientiousness, motivation, and performance. Journal of Vocational Behavior, 63(3), 347-367.

Bose, I., \& Emirates, U. A. (2018). Employee empowerment and employee performance: An empirical study on selected banks in UAE. Journal of Applied Management and Investments, 7(2), 71-82.

Brown, M. P., Sturman, M. C., \& Simmering, M. J. (2003). Compensation policy and organizational performance: The efficiency, operational, and financial implications of pay levels and pay structure. Academy of management Journal, 46(6), 752-762.

Dessler, G. (2011). Fundamentals of human resource management. Pearson Higher Ed.

Dulebohn, H. J., Ferris, R. G., \& Stood, T. J. (1995). Handbook of human resource management.

Feraro-Banta, L., \& Shaikh, S. . (2017). Relation of compensation and benefits on employees' performance. International Advanced Research Journal in Science, Engineering and Technology, 4(5), 175-183.

Ferris, G. R., Mitchell, T. R., Canavan P. J., D., F. D., \& Hopper, H. (1995). Accountability in Human Resource Systems. Handbook of human resource management, 175196.

Fornell, C. G., \& Larcker, D. F. (1981). "Evaluating structural equation models with unobservable variables and measurement error". Journal of Marketing Research,, 18(1), 3950.

Geralyn. (2007). Human Resource Management Basic: Small verses Large Firm Practices. Virginia Hernandez. The University of Texas of Premium Basis.

Hair, J. F., Ringle, C. M., \& Sarstedt, M. (2014). Indeed a silver bullet. Journal of Marketing theory and Practice, 19(2), 139-152.

Hall, A. T., Frink, D. D., Ferris, G. R., A, H. W., \& G, K. C. J. B. M. (2003). Accountability in human resources management New directions in human resource management, 29-63. 
Hameed, A., Ramzan, M., Zubair, \& K., H. M. (2014). Impact of compensation on employee performance (empirical evidence from banking sector of Pakistan). International journal of business and social science, $5(2)$.

Han, Y., \& Hong, S. (2019). The impact of accountability on organizational performance in the US federal government: The moderating role of autonomy. Review of Public Personnel Administration, 39(1), 3-23.

Hanaysha, J. (2016). Examining the effects of employee empowerment, teamwork, and employee training on organizational commitment. Procedia-Social and Behavioral Sciences, 298-306.

Hong, S. (2017). What are the areas of competence for central and local governments? Accountability mechanisms in multi-level governance. Journal of Public Administration Research and Theory,, 27(1), 120-134.

Iqbal, N., Ahmad, N., \& Javaid, K. (2013). Impact of Employee Empowerment on Employee Performance in the context of Banking Sector of Pakistan. pinnacle business management.

Ivancevich, J. M., W. F., W., \& Glueck, F. (1989). Foundations of Personnel/Human Management, , 409.

Jean, K., T., \& N.K. (2017). Effect of compensation strategies on employee performance: A Case Study of Mombasa Cement Limited. . International Robert, A. Journal of Innovative Social Sciences \& Humanities Research, 5(3), 25-42.

Kamunge, S, M., Njeru, A., \& I., T. O. (2014). Factors affecting the performance of small and micro enterprises in Limuru Town Market of Kiambu County, Kenya. International Journal of Scientific and Research Publications, 4(12), 1-20.

Kroon, M. B., Van Kreveld, D., \& Rabbie, J. M. (1992). Group versus individual decision making: Effects of accountability and gender on groupthink. . Small Group Research, 23(4), 427-458.

Lerner, J. S., \& Tetlock, P. E. (1999). Accounting for the effects of accountability. Psychological bulletin, 125( 2), 255.

Mehran, H. (1995). Executive compensation structure, ownership, and firm performance. Journal of financial economics, 38(2), 163-184.

Mohapatra, I., \& Sundaray, B. K. (2018). Impact of employee empowerment on employee performance. International Journal of Advanced Technology and Engineering Research, National Conference on Recent Trends in Science, Technology and Management Vol. 1, 98-102.

Nadeem, M. T., Zia-uD-din, M., Riaz, W., Shafique, M. Z., \& Sattar, A. (2018). The effects of employees empowerment on organizational performance : a case of hotel industry in Pakistan. International Journal of African and Asian Studies, 47, 89-94.

Okeke, M. N., \& Ikechukwu, I. A. (2019). Compensation Management and Employee Performance in Nigeria. International Journal of Academic Research in Business and Social Sciences, 9(2).

Radin, A., B., Dubnic, J., M., \& Frederickson, H. G. (2011). Accountable Governance: Problems and Promises.

Rajalingam, Y., Jauhar, J., \& Bashawir, A. G. (2015). A study on the impact of empowerment on employee performance: The mediating role of appraisal. nternational Journal of Liberal Arts and Social Science, 3(1), 92-104.

Richard, T. a. M., M. . (2009). Challenges of performance management in contemporary scenario. Journal of Business and Psychology, 39((2)), 56-71.

Shalley \& Gilson. (2004). What leaders need to know: A review of social and contextual factors that can foster or hinder creativity. The leadership quarterly, 15((1)), 33-53.

Shields, J., Brown, M., Kaine, S., \& North-Samardzic, A. (2015). Managing employee performance \& reward: Concepts, practices, strategies. Cambridge University Press.

Snell, B. (2010). Managing human resources. Cengage Learning. 
Sundaray, M. (2018). Impact of employee empowerment on employee performance. International Journal of Advanced Technology and Engineering Research, National Conference on Recent Trends in Science, Technology and Management, 1, 98-102.

Tetlock, P. E. (1985). Accountability: A social check on the fundamental attribution error. Social psychology quarterly, 227-236.

Tetteh-Annor. (2014). Effect of compensation management on employee performance at the St. Michael's Catholic Hospital. Pramso (Doctoral dissertation)

Yilmaz. (2015). Revisiting the impact of perceived empowerment on job performance. Turizam, 19(1), 34-46. 